\title{
Changes in Transit Accessibility to Food Banks in Toronto during COVID-19
}

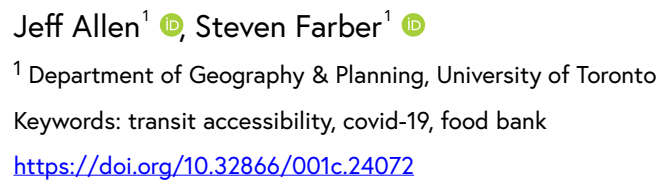

Findings

Food banks provide an essential lifeline for those experiencing food insecurity. In Toronto, Canada, 21 new food bank locations opened between February, 2020 and May, 2021 in response to the COVID-19 pandemic. In this article, we measure and map how this has improved public transit accessibility to food banks, with a focus on improvements among low-income residents. We find that the percent of low-income residents that can reach a food bank within a 20 minute one-way transit trip improved from $50 \%$ to $60 \%$ during this time period.

\section{Questions}

Food banks provide groceries to those who cannot afford to purchase them at market rates. In Toronto, food banks witnessed increased usage due to the economic impacts caused by the COVID-19 pandemic and growing prevalence of food insecurity (Feed Ontario 2020; Polsky and Gilmour 2020; Draaisma 2021). In response to this, 21 new food bank locations opened between February, 2020 and May, 2021 across the city.

The objective of this analysis was to map transit accessibility to food banks in Toronto, and examine how transit accessibility changed during the COVID-19 pandemic due to the opening of new food bank locations as well as changes in transit schedules. We also seek to answer how accessibility levels, and changes in accessibility, vary among population groups more likely to use food banks like those in low-income households and for households that do not have a car. While focused on findings in Toronto during COVID-19, these methods could be applied elsewhere to assess food bank supply and system performance in other contexts.

\section{Methods}

Data pertaining to the addresses of food banks were provided by Daily Bread Food Bank. These locations included an indicator of whether they were open prior to COVID-19 (February, 2020) and in May, 2021. In February, 2020 there were 70 food bank locations open to the overall population and in May, 2021 there were 91 locations.

We measure transit accessibility as the one-way travel time by public transit to the nearest food bank in minutes from locations across Toronto. This is a dual measure of accessibility (Cui and Levinson 2020) that has previously been used to map transit accessibility to healthy food retailers in Toronto (Widener et al. 2017). For our study, we generated a fine-grained hexagonal grid in order 
to map accessibility to food banks with even spatial representation across the entire city. Each hexagon in the grid has an apothem of 75 metres and there are 35,970 of these hexagons in total across the City of Toronto.

For our analysis, one-way travel times by public transit were estimated from the centroid of each hexagon cell to the nearest food bank for both time periods (February, 2020 and May, 2021). Travel times were computed using the transportation network routing software r5r (Pereira et al. 2021). Two multimodal transport network graphs were created for analysis based on transit schedule data for February, 2020 and May, 2021, respectively. Transit schedules were acquired as GTFS data from the Toronto Transit Commission (TTC) and walking network data is from OpenStreetMap. Travel times by transit include walking to and from stops, waiting for a vehicle, in-vehicle travel time, and transfer time (if applicable). Travel times were estimated based on a 3pm departure time for a typical weekday, a time of day when most food banks are open. The minimum one-way travel time from each hexagon cell was then mapped to examine spatial patterns across the city.

We further analyzed how accessibility varies among population groups more likely to use food banks such as low-income residents, visible minorities, recent immigrants, and residents in households without cars. Data on low-income residents, visible minorities, and recent immigrants (2011-2016) are from the 2016 Canadian census (Statistics Canada 2016). We use two measures of lowincome status as both are commonly used in Canadian research; the after-tax Low-Income Cut-Off(LICO), defined as a function of a consumer price index (Statistics Canada 2017a), and the after-tax Low-Income Measure (LIM), based on regionally adjusted median household incomes (Statistics Canada 2017b). Data on zero-car households are from the Transportation Tomorrow Transportation Tomorrow Survey (2016). All these data are provided at the census Dissemination Area level (approximately 400-700 people). Comparative analysis was conducted at the smaller Dissemination Block level in order to account for varying levels of accessibility within Dissemination Areas. To do so, we dis-aggregated census data to Dissemination Blocks based on the ratio of block population to Dissemination Area population and the accessibility measures generated at hexagons were linked to Dissemination Blocks via areal interpolation. Results are summarized with descriptive statistics and cumulative distribution plots. All code, data, and figures for this analysis are hosted openly on GitHub.

\section{Findings}

Figures $\underline{1}$ and $\underline{2}$ visualize transit accessibility to food banks in February, 2020 and May, 2021, respectively. In both time periods, the majority of Toronto (both in terms of population and area) can reach food banks within 30 minutes, but only a minority within 15 minutes by public transit. The small dots on the maps identify the spatial distribution of people living below the poverty line based on the Low-Income Cut-Off (LICO). 


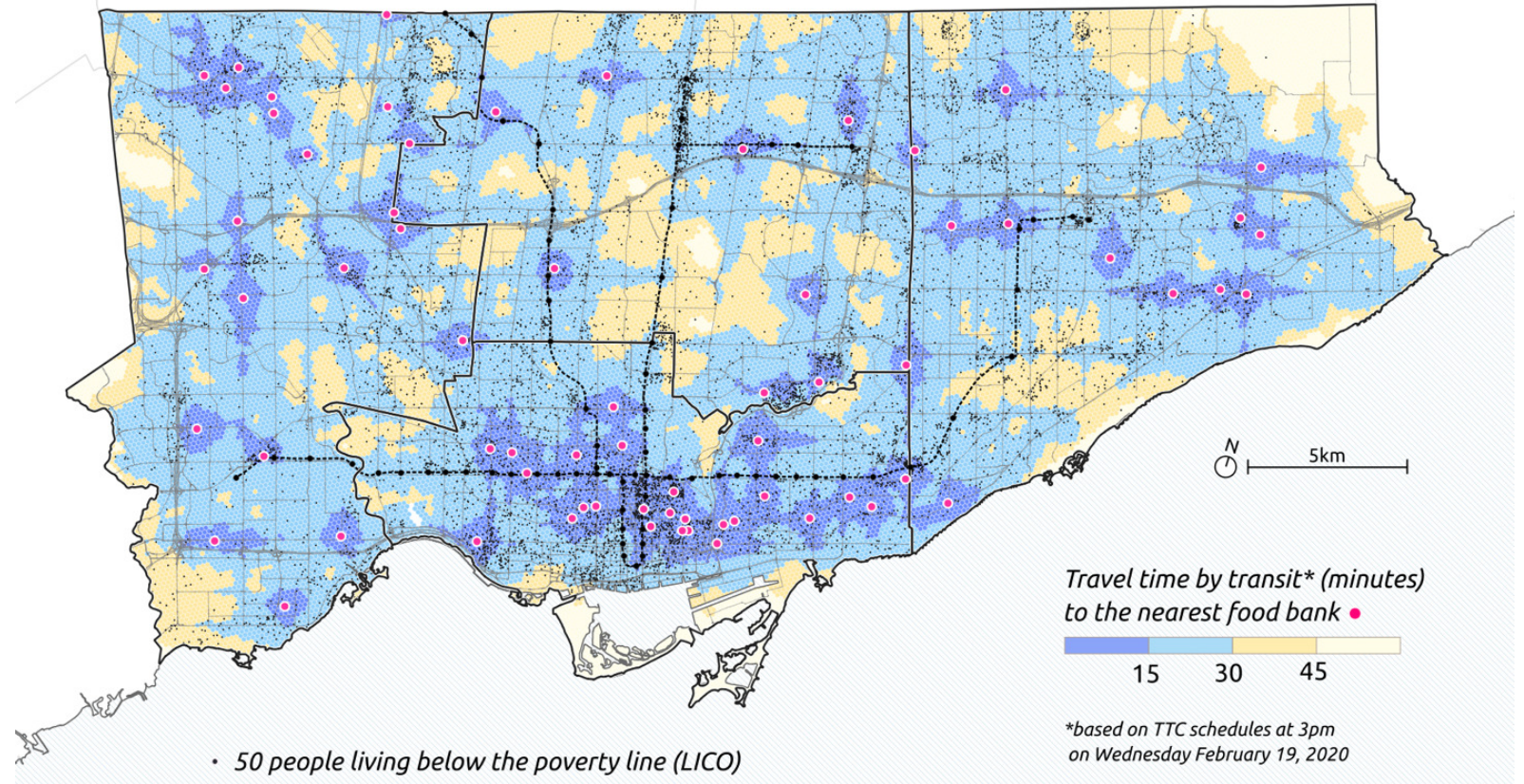

Figure 1: Transit accessibility to food banks in Toronto in February, 2020

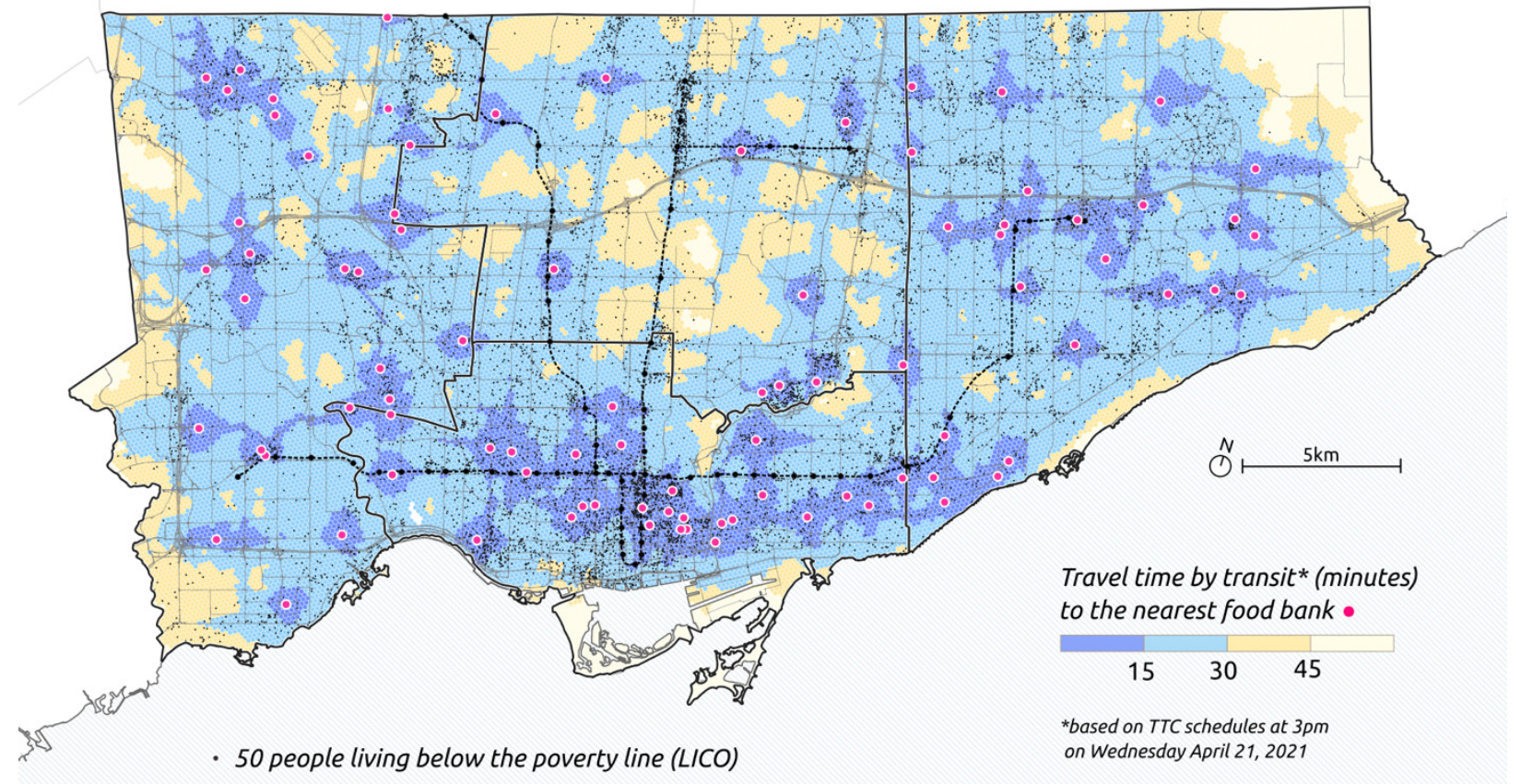

Figure 2: Transit accessibility to food banks in Toronto in May, 2021

Figure 3 is a map of the difference in accessibility to food banks for the two time periods. Green areas are where one-way travel times have decreased (i.e. an improvement in accessibility to food banks) while orange areas are where it has increased (i.e. a decline in accessibility to food banks). Clearly the recent 


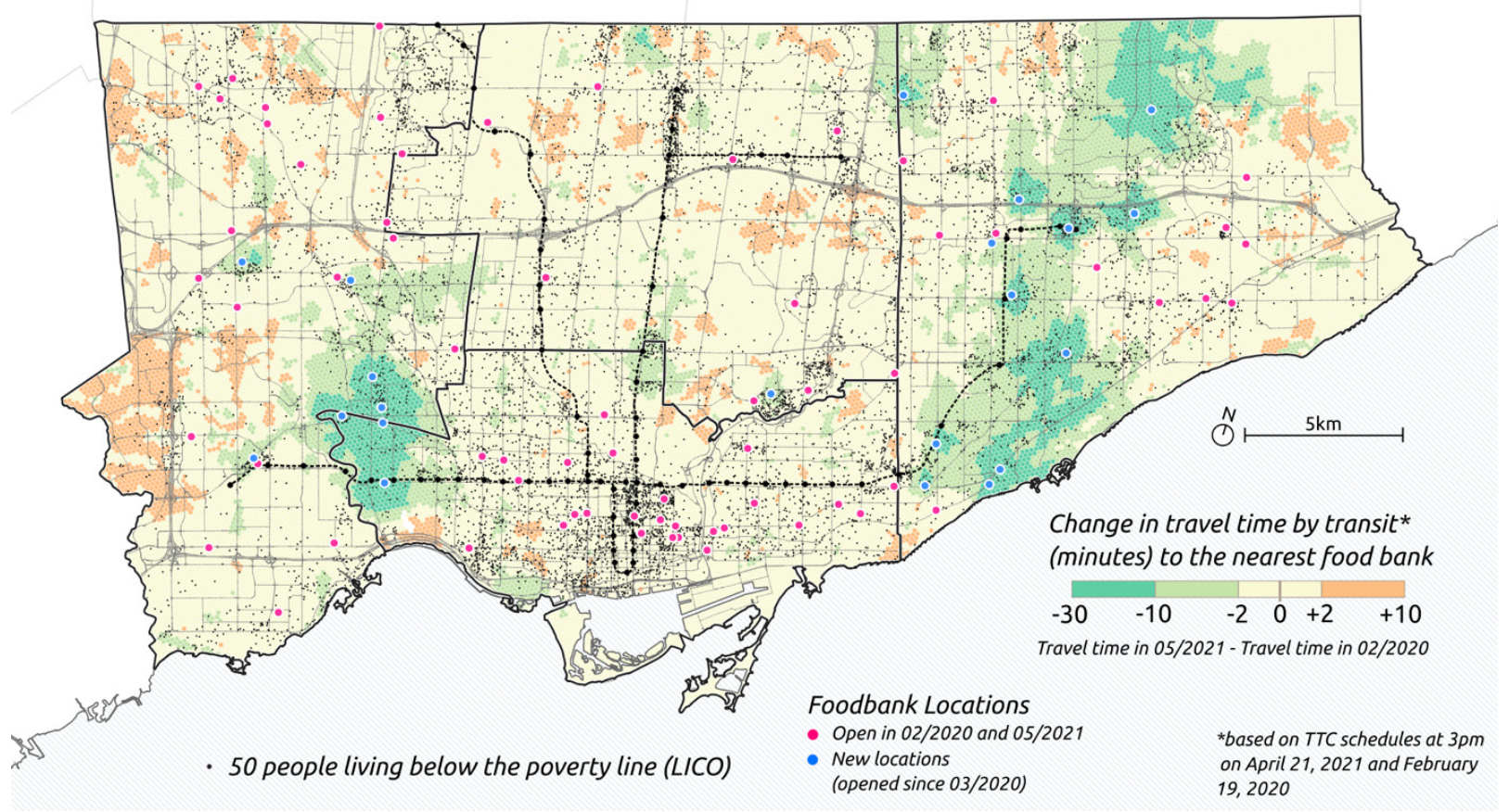

Figure 3: Difference in transit accessibility to the nearest food bank (May, 2021 - February, 2020)

Table 1: Average travel time by public transit to the nearest food bank for different population groups

\begin{tabular}{lcccc}
\hline & \multicolumn{3}{c}{ Average Travel Time (minutes) } & \\
& February, 2020 & May, 2021 & Difference & \% Difference \\
\hline Overall Population & 21.00 & 19.75 & 1.25 & $6.0 \%$ \\
In a low-income household (LIM) & 19.75 & 18.36 & 1.39 & $7.0 \%$ \\
In a low-income household (LICO) & 19.61 & 18.29 & 1.32 & $6.7 \%$ \\
Visible minority & 20.87 & 19.40 & 1.47 & $7.0 \%$ \\
Recent immigrant (2011-2016) & 20.19 & 19.04 & 1.15 & $5.7 \%$ \\
In a zero-car household & 18.96 & 17.82 & 1.14 & $6.0 \%$ \\
\hline
\end{tabular}

opening of food bank locations has substantially increased accessibility in the neighbourhoods surrounding them. The orange areas witnessing declines in accessibility can be attributed to changes in transit service over this time period.

In Table 1, we report the average one-way travel time to the nearest food bank for different population groups. Overall, lower socio-economic groups have shorter one-way travel times by transit, and thus greater levels of accessibility, than the overall population. New food banks have provided greater accessibility improvements to low-income and visible minority residents, on average, when comparing between the two time periods.

In Figure 4 , we plot cumulative distribution functions (CDFs) of the one-way travel time to the nearest food bank for each population group for both time periods. Each point on the plot represents the percent of the population noted on the Y-axis that can reach a food bank within a one-way travel time noted on 

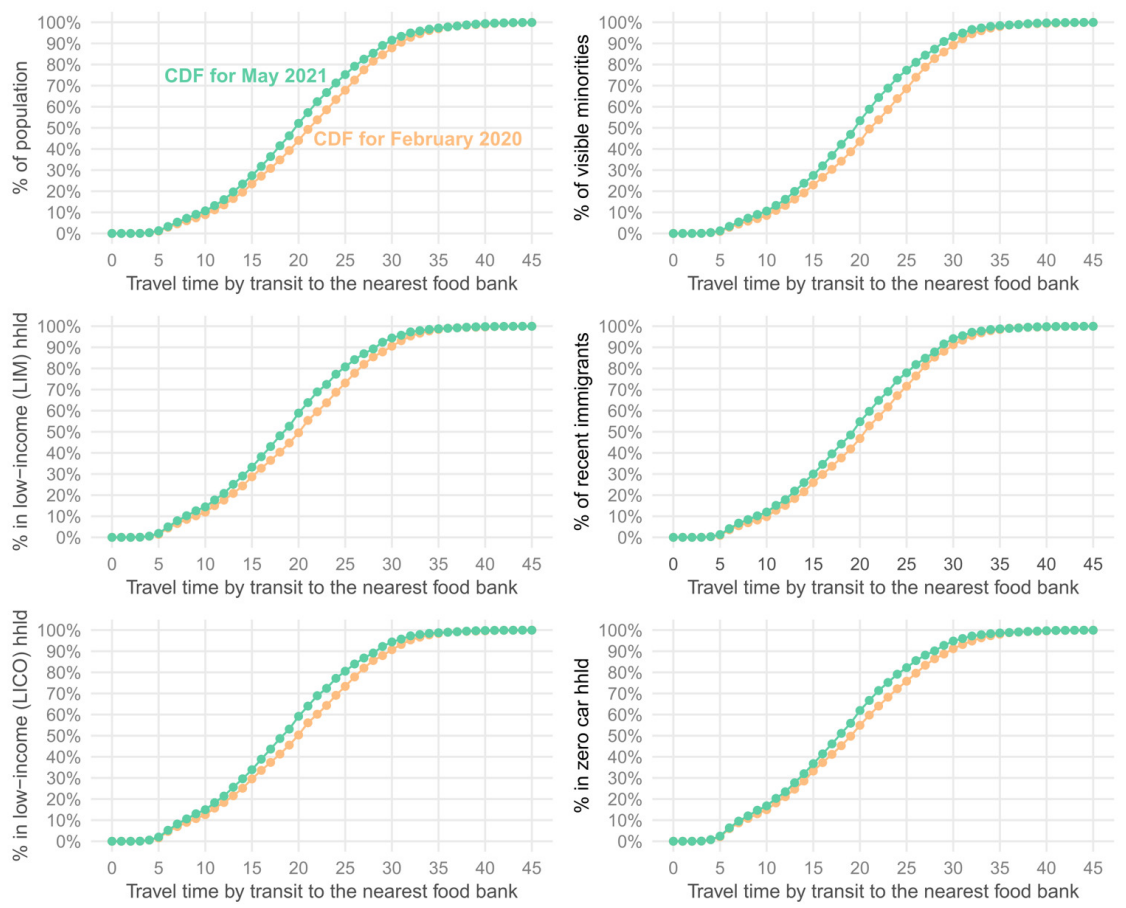

Figure 4: Cumulative distribution plots of travel time to the nearest food bank for different populations

the X-axis. For example, in February, 2020, 50\% of the low-income population could reach a food bank within a 20-minute transit trip, while in May, 2021, $60 \%$ of the low-income population could reach a food bank within a 20 -minute transit trip.

\section{Acknowledgements}

We would like to thank Daily Bread for their immeasurable efforts operating food banks in Toronto. We specifically want to thank Talia Bronstein and Natasha Martin at Daily Bread as well as Lisa Helm and Luc Hartwick at Rocketman for their comments and suggestions. 


\section{REFERENCES}

Cui, Mengying, and David Levinson. 2020. "Primal and Dual Access." Geographical Analysis 52 (3): 452-74. https://doi.org/10.1111/gean.12220.

Draaisma, M. 2021. "Toronto's Daily Bread Food Bank Collects over 25,000 Pounds of Food at Spring Drive-Thru Event.” CBC News, April 3, 2021. https://www.cbc.ca/news/canada/toronto/ daily-bread-food-bank-spring-drive-thru-event-contactless-event-1.5974904.

Feed Ontario. 2020. "The Hunger Report: The Impact of COVID-19 on Food Bank Use in Ontario.” https://feedontario.ca/wp-content/uploads/2020/11/Hunger-Report-2020-FeedOntario-Digital.pdf.

Pereira, Rafael H. M., Marcus Saraiva, Daniel Herszenhut, Carlos Kaue Vieira Braga, and Matthew Wigginton Conway. 2021. "r5r: Rapid Realistic Routing on Multimodal Transport Networks with R5 in R.” Findings, March. https://doi.org/10.32866/001c.21262.

Polsky, J.Y., and H. Gilmour. 2020. "Food Insecurity and Mental Health during the COVID-19 Pandemic." Health Reports 31 (12): 3-11. https://www150.statcan.gc.ca/n1/pub/82-003-x/ 2020012/article/00001-eng.htm.

Statistics Canada. 2016. “Census Profile, 2016 Census.” https://www12.statcan.gc.ca/censusrecensement/2016/dp-pd/prof/details/download-telecharger/comp/page_dl-tc.cfm?Lang=E.

- - - 2017a. "Low Income Cut-Offs." Census Dictionary. https://www12.statcan.gc.ca/censusrecensement/2016/ref/dict/fam019-eng.cfm.

-_- 2017b. "Low Income Measure.” Census Dictionary. https://www12.statcan.gc.ca/censusrecensement/2016/ref/dict/fam021-eng.cfm.

“Transportation Tomorrow Survey.” 2016. Data Management Group. University of Toronto. http://dmg.utoronto.ca/transportation-tomorrow-survey/tts-reports.

Widener, Michael J., Leia Minaker, Steven Farber, Jeff Allen, Brigitte Vitali, Paul C. Coleman, and Brian Cook. 2017. "How Do Changes in the Daily Food and Transportation Environments Affect Grocery Store Accessibility?” Applied Geography 83 (June): 46-62. https://doi.org/10.1016/ j.apgeog.2017.03.018. 